\title{
The teaching of the function at high school: The graphic representation of a function at first year, section experimental sciences
}

\author{
Mohamed Khalil Zarhouti, Mohammed Mouradi, Abdelouahed El Maroufi \\ Interdisciplinary Research Laboratory Teaching of Science and Technology \\ Faculty of Science Dhar El Mahraz Sidi Mohamed Ben Abdellah University, Fez Fez Atlas-Fez- Morocco
}

\begin{abstract}
The study of the concept of the graphic representation in Moroccan first year Baccalaureate, section experimental sciences, finds its origin in the mathematics curriculum that gives an important place to the study of functions. This research aims at exploring how this concept is presented in the Moroccan mathematics curriculum using the theoretical framework of didactic transposition, as it was developed by Y.Chevallard (1985) and that of R. Duval (1993) on the semiotic representations, specifically on the graphic register, and on the conversion of the algebraic register to the graphic register. Our article relies more precisely on the ability of students to solve various tasks involving the use of graphic representation of a function.
\end{abstract}

Key words: Graphic representation, function, teaching mathematics in high school. Register representation. Didactic transposition.

\section{Introduction}

The graphic representation of a function is one of the major pillars of the study of a function in the first year Baccalaureate, experimental sciences, in Morocco. We notice that several students have difficulties in accomplishing this task (Tall \& Razali, 1993). As a result, our choice to analyse the difficulties to which the students are confronted, in the process of the assimilation and conceptualization of this notion, clears itself by:

$>$ The first year Baccalaureate, experimental sciences (a class which precedes the final class of secondary school) really constitutes a fundamental class where are taught the basic notions to draw a curve of a numerical function, to know derivative function, inflection point, infinite branches, particularly asymptotes, asymptotic directions, tangent point, etc. All these tools make easier the drawing of the graphic representation of a function.

$>$ The ministry guidelines insist on mathematical activities which take into account the graphic representation of functions (Ministry of National Education, 2007).

$>$ The graphic presentation of polynomial, rational, trigonometric and irrational functions, in first year Baccalaureate, experimental sciences constitutes a cornerstone to approach that of logarithms and exponential functions in second year Baccalaureate, which constitutes the final class of the secondary school in the Moroccan educational system (Ministry of National Education, 2007).

Our choice of this topic guides us to study the treatment within the graphic register which is part of the theory of semiotic representation according to R. Duval $(1993,1995)$, as well as the didactic transposition of the notion, the graphic representation; this transposition was developed by Y. Chevallard (1985). The analysis of the passing of the knowledge to teach to the knowledge really taught according to P. Tavignot (1995) must be the concern of syllabi, comments, textbooks, lesson plans and the real practices of the teachers in class.

In the light of the National Charter of Education and Training (1999), the last reform to the mathematics curriculum in Morocco in 2006 introduced a new way of teaching the notion of the function. In fact, we first teach linear and affine functions in the third year of intermediate school, then in the common core year of high school, option sciences (The class which comes just before the first year Baccalaureate, experimental sciences), we approach other notions closely linked to functions such as: parity, sense of variation, variation table, graphic representations of usual functions of type $x \rightarrow a x^{2}$ and $x \rightarrow a / x$. However, the classical theoretical notions of the analysis such as limit, derivation,... do not appear until the first year Baccalaureate, experimental sciences (Ministry of National Education, 2007).

The graphic representation of numerical functions of a real variable, according to G. Chauvat (1998) identifies three modes of the functioning of the graphic representations:

1. The nomograph Mode. This mode corresponds to the functioning of the graph as an abacus and as a tool of calculation:" the graph is then an efficient algorithmic medium to get numerical results (approached in general) by local procedures".

2. The ideogrammatic Mode. In this mode, the graph works as an ideogram"As graphic sign which refers to an idea". 
3. The operating Mode. In this mode, the graph works as:" An interactive process which is non algorithmic: The task cannot be performed without the graph, but the answer is not directly given by the graph; it must be constructed by the subject in interaction with the graph, without having a standardized algorithm".

In the case of the usage of graphic representations in intermediate school, G. Chauvat (1998) finds that during the didactic treatment of the meeting of the notions of curves with functions, the recourse to ideogrammatic or nomograh modes is privileged. As regards the teaching of analysis at high school, I. Bloch (2000) points out that the graph is seen as the outcome of a series of algorithmic operations and not as a tool of proof or construction. She also points out that the graph is only used under an ideogrammatic model and that its treatment is principally punctual, which constitutes an obstacle for a total functioning of the graphic representations.

According to G. Chauvat (1998), I. Bloch (2000, 2002) and Mr. Maschietto (2001), the functioning of the graphic representations in secondary education is in most cases of an ideogrammatic type. This mode of functioning of the graph puts the emphasis on the total aspect of the graphic representations.

\section{Theoretical framework and review of the literature}

The notion of the graphic representation of a function is a representation of the graphic register by excellence; it is for this reason that we adopt the theory of Raymond Duval on semiotic representation of the different registers. Besides, this notion develops in the course of the time from the knowledge to teach towards the knowledge taught, which encourages us to adopt the theory of the didactic transposition which is postulated by Y. Chevallard. The literature which works on these two theories is abundant.

Within the framework of the theory of R. Duval, the works of V. Padilla Sanchez (1992) and E.C. Lémonidis (1990) are interested in the activity of treatment, founded principally on transformations inside a register, as well as the works of I. Gutman-Retamal (1989) which were interested in the activity of conversion between two registers. We also have the works of H. Femando (2004) which put the emphasis on the role of semiotic representations in the construction of mathematical concepts as well as in the analysis of the productions of the students. Also B. David, N. Kostas and V. Laurent (2012) stress the importance of the registers of representation and the types of tasks in mathematical activity.

As regards the works relative to the theory of didactic transposition, Mr. Artaud (1997) emphasizes that the first studies on transpositif processes already identified two big sets of conditions allowing mathematics to exist in the system of education. Textbooks constitute the first stage of the internal transposition of the knowledge to teach, as it is defined by the ministry guidelines, towards the knowledge indeed taught in classes. So, according to the terms of L. Ravel (2003), they constitute a preparatory process of knowledge. The main purpose is to know the effect of the didactic transposition in the precocious appearance of graphs at the beginning of high school. The works of G. Chuavat (1999) show how the didactic transposition of the notion of the function at intermediate school can reinforce obstacles having appeared historically, across notably recourse to an ideogrammatic mode in the graph.

Besides, we draw inspiration from the works of E. Lacasta (1995) based on the theory of didactic transposition to study graphic phantasm in the students of secondary school.

\section{1- Registers of representation}

R. Duval (1995) considers that to make the perception of the mathematical objects accessible, representations are needed. He also points out the importance of a recourse to several registers of representation and the recognition of the mathematical objects in these registers, which helps not to merge them with their representations:" The coordination of several registers of semiotic representation seems fundamental for an abstract apprehension of objects: it is necessary that the object is not merged with its representations and that it is recognized in each of its possible representations".

A semiotics system is defined by R. Duval (1993) as a register of representation, if it allows the three following cognitive activities:

1. The formation of an identifiable representation as a representation in a given register.

2. The treatment of a representation, that is to say its transformation in the same register where it was formed.

3. The conversion of a representation, that is to say the transformation of this representation into a representation of another register by keeping the totality or only a part of the contents of the representation.

For R. Duval, the recourse to several registers is a necessary condition so that the mathematical objects cannot be merged with their representations and can be recognized through each of them. Within this framework, R. Duval underlines that the notion of the function requires the use of several registers:

$\checkmark$ Symbolic register (variation table) 
$\checkmark$ Numerical register (value table)

$\checkmark$ Graphic register (curves, graphic representation)

$\checkmark$ Algebraic register (representation by formulae)

As for global and punctual properties, Fr. Vandebrouk (2011) speaks about the aspects which a function can take:

$>$ Certain properties are punctual at a point $x_{0}$, which is they depend only on the value of the function in the point $x_{0}$. For instance, the statement $f\left(x_{0}\right)=3$ is a punctual property about which we can say nothing on the value of $f\left(x_{1}\right)$ when $x_{1} \neq x_{0}$.

$>$ Other properties are global, that is they are valid on intervals: parity, periodicity, growth, continuity, and derivability...

\subsection{Didactic transposition}

In didactics, the question of knowledges was initially treated through the notion of didactic transposition since the work of Y. Chevallard (1985), who established the distinction between academic knowledge, the knowledge to teach and the knowledge taught. This analysis brings about the different origins of knowledges, as well as the peculiarity of academic knowledge, as part of researches in the didactics of mathematics. The notion of didactic transposition, often taken back by other research fields, and especially by didactics of disciplinary knowledges, was used to explain the transformations especially between academic knowledge and the knowledge to teach. The internal transposition of knowledges, that is to say, the transformations of the knowledge to teach to the knowledge taught, where the role of the teacher emerges in an important manner, was subsequently studied in didactics, with the aid of other theoretical tools.

\section{Dimension of difficulty facing the graphic representation of a function}

Relying on our conceptions and our experiences, we review the difficulties met by the students during the graphic representation, within the framework of R. Duval's theory and that of didactic transposition. We can perform an a priori analysis (Mr Artigue (1989)), by classifying these difficulties following three dimensions, namely difficulties of epistemological nature, those of cognitive nature and those of pedagogic nature.

\subsection{Difficulties of epistemological nature}

According to B. Sarrazy (1995), any contract bears an epistemology. So, due to the didactic contract, the first year students, experimental sciences, have no habit of searching the points of meeting of the curve with the axis of coordinate system, and the infinite branches during the drawing of the graphic representation of a function. Another important aspect to take into account during the treatment of the graphic register manifests itself by making the difference between asymptotes and asymptotic directions. This feature requires an important conceptual change, because habitually, the student in the previous years, draws the curves of affine, linear functions, and in common core, she or he draws the curves of common functions without using these new concepts. Obtained results show that the difficulties met by the big majority of students have links with epistemological characteristics of the expressions of the form: $\lim _{x \rightarrow+\infty} f(x) / x=+\infty, \lim _{x \rightarrow+\infty} f(x) / x=0$. In fact, the students do not succeed in interpreting these limits geometrically especially during the drawing of graphic representation. These results show that these students find difficulties in conversing the algebraic register to the graphic register. This difficulty implies that the didactic transposition of the teaching of graphic representation poses the problem of how to accomplish this type of task, more precisely the treatment within the graphic register and at the level of articulation of both the algebraic and graphic registers. Moreover, we have also found students who do not succeed in implementing certain knowledge, owing to prototypical pictures linked to the mathematical notions at play. Let us name, as an example, the interpretation of the sign of the second derivative function at the level of the graphic register. When the student wants to draw the curve, she or he ignores the drawing of the tangent, the asymptotes and the asymptotic directions, because she or he is accustomed to drawing the curves of affine and linear functions, the curves of functions of second degree and homographic functions, without using the previous notions. There is also the fact, as for the line of the curve, that the students have tendency to forget units of measurements, which poses problems of construction.

\subsection{Difficulties of cognitive nature}

Numerous observations of the daily practice of the teachers show that the students have difficulties with the notion of the graphic representation of a function (according to G. Chauvat, 1998). Nevertheless, the teaching of this concept is fundamental, because from the cognitive point of view, the complexity of the notion requires the development of several structures of thought in the students (according to J. Moreno, 2006). The majority of students find difficulties in drawing a tangent right in the curve of a function. More than that, they find it difficult to determine the points of meeting between a curve and the $x$-axis in order to solve the 
equation $f(x)=0$. In fact, they determine the abscissa of this point but they do not understand that its ordinate sound is worth 0 . Also several students do not succeed in determining the sign of $f(x)$ from the graphic representation of the function $\mathrm{f}$, which is the result of a cognitive gap that links between the algebraic register and the graphic register. Besides, we notice that several students do not assimilate well the second derivative and consequently do not succeed in determining the inflection point which requires two things in fact: Firstly solving the equation $f^{(2)}(x)=0$. Secondly $f^{(2)}(x)$ should change sign in the point $x_{0}$ where $f^{(2)}\left(x_{0}\right)=0$.

Moreover, at the level of the treatment, we observe that a good many students do not make a link between the resolution of $f^{(\mathbf{1})}(x)=0$ and the extrema values of the curve which are translated by tangent parallels in the $x$-axis. On the other hand, we find several students with difficulties linked to the calculation of limits which has consequences on the construction of the graphic representation, especially at the level of the oblique asymptotes and at the asymptotic directions. As a result, we can say that the didactic transposition of the notion of limit constitutes a cognitive obstacle, which prevents the student from accomplishing this type of task of conversion.

However, the treatment within the graphic register poses a big problem to the students, especially at the level of interpretations by concluding results across the graphic representation of this function in order, for instance, to study the sign of $f(x)$ across this graph.

\subsection{Difficulties of pedagogic nature}

The official curriculum recommends the drawing of the graphic representation of diverse functions, but this objective is out of reach because the Moroccan school system develops generally in classes with excessive number of students (at least 40 students per class). On top of that, having a very loaded curriculum, the students do not have the opportunity to diversify their activities of treatment within the graphic register or conversion of or towards this register; which restricts, as a result, the good assimilation of the different registers, especially at the level of the treatment in the graphic register.

Moreover, this difficulty may be due to the didactic transposition of the teaching of this concept which does not always insist on the progression of stages: First we draw the tangent in the curve (C) of a function parallel in the $x$-axis, then the asymptotes which are vertical, horizontal or oblique. We pass to the determination of the points of meeting of (C) with the axis of coordinates, and finally we end, with the aid of the variations table, with the conversion of the symbolic register to the graphic register to draw the curve representing the function $f$, by respecting the asymptotic directions of $(\mathrm{C})$, and the extrema values of $(\mathrm{C})$. We think that this progression guarantees the good realization of the task of the construction of the graphic representation of this function. As a result, the teacher finds herself/himself obliged to approach these registers briefly and to follow this progression in order to deserve a good feedback from the administration and the inspector. These two are more interested in the record book than in the teaching method and in the assimilation of the learners. This system of assessment constitutes one of the major pedagogic difficulties that would prevent the teacher from reaching the target of drawing the graphic representation of various functions.

\section{Purpose of study and research questions}

Further to our concerns raised in the introduction and to our points made in the review of literature, the objective of this research is to show the importance of drawing the graphic representation of a function, that of interpreting it in a correct way at the level of the treatment as well as a good mastery of the articulation between the algebraic and graphic registers. This is because the research for a way where the didactic transposition of the knowledge to teach to the knowledge taught concerning the concept of the graphic presentation of a function makes easier and optimizes the line of this curve. This objective is expressed by the following research questions:

a. Can the didactic transposition of the notion of the curve reinforce the difficulties which confront the students when dealing with this concept?

b. Is the student able to draw the graphic representation of a function both at the level of the treatment and at the level of the articulation between the graphic and algebraic register as regards the graphic representation of a function?

c. Besides, what place does the graphic representation of a function take in the activities of treatment and conversion between the graphic and algebraic registers?

\section{Research methodology}

To reach this target, and by referring to the dimensional classification worked out before, we have used a questionnaire and qualitative analyses of the oral productions of the students. These analyses confirm or supplement the statistical analyses of the questionnaire. 


\section{1- The population concerned by this research work}

By relying on basic concepts about the graphic representation received in the class of common core of high school, the class which precedes the first year class, we have given the same questionnaire to three classes of the first year experimental sciences of the same school, about 122 students; these spent one hour to do the three activities making up this questionnaire.

\section{1- Elaboration of the questionnaire}

To reach our target, we have designed a questionnaire which aims at questioning the capacity of the students to solve different tasks putting into play the graphic representation of a function as part of the didactic transposition used in the teaching of this concept, by drawing inspiration from registers of representation either at the level of the treatment or that of the conversion of the algebraic register to the graphic register and conversely.

We have chosen three activities from the textbooks of mathematics of the first year Baccalaureate, experimental sciences (July and August, 2006), adopted by the Ministry of Education.

\section{First activity:}

Let $f$ be a numerical function defined by: $f(x)=x^{3}-3 x$

1) Determine the infinite branches of $\left(C_{f}\right)$ of $f$.

2) Determine the inflection point and the concavity of $\left(C_{f}\right)$.

3) Let $(D)$ be to the tangent $\left(C_{f}\right)$ at the point 0 , draw $(D)$ and $\left(C_{f}\right)$

\section{Second activity:}

Let $\mathrm{g}$ be a numerical function defined by: $g(x)=x+1+\frac{1}{x}$

1) Determine $D_{g}$ the domain of definition of the function $g$, and then determine the limits to the boundaries of $D_{g}$.

2) Determine the asymptote $(T)$ oblique of $\left(C_{g}\right)$, the curve representing the function $g$.

3) Determine the relative position from the line $(T)$ and $\left(C_{g}\right)$.

4) Draw $(T)$ and $\left(C_{q}\right)$.

Third activity:

We consider $h$ a numerical function of real variable $x,\left(C_{h}\right)$ its graphic representation in an orthonormal coordinate $(\mathrm{O}, \vec{i}, \vec{j})$, (d) is the asymptotic line of equation $\mathrm{y}=\frac{1}{2} \mathrm{x}+1$. From $\left(C_{h}\right)$ below, answer the following questions:

1) Determine $D_{h}$, the domain of definition of the function $h$.

2) Determine $\lim _{x \rightarrow-\infty} h(x) / x$ and $\lim _{x \rightarrow+\infty} h(x) / x$.

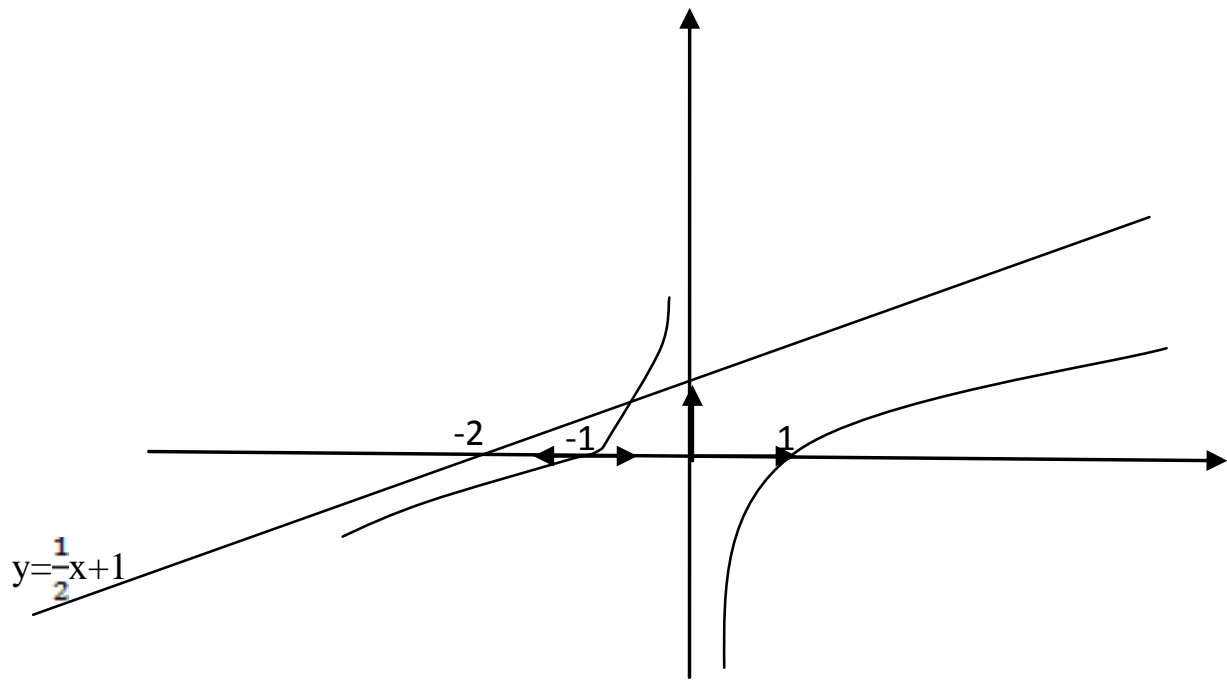

$\left(C_{h}\right)$ The graphic representation of the function $h$ 


\section{Analysis and interpretation of results}

This is about statistical analyses of data gathered from the questionnaire and the analysis of the oral productions of the students.

\subsection{Statistical analyses of data gathered from the questionnaire First activity: Question 1}

Before analyzing this question, we refer to the ministry guidelines which stress the importance of studying the infinite branches (asymptotic direction and asymptotic line) and interpreting some limits of a function graphically with the aim of refining its graphic representation (Ministry of national education, 2007). So, the infinite branches play an important role both at the level of the treatment within the graphic register and at the level of the conversion of the algebraic register to the graphic register by putting the emphasis on the punctual aspect of the function (in the sense of Vandebrouck) and more particularly on limits. To work out the concepts of "asymptotic"direction and of "asymptotic line", the teacher suggests activities which lead the students to link limits defining the two last concepts and to represent the function being discussed graphically.

This task constitutes the spinal column, within this algebraic register. Almost $60 \%$

students) carry out this work, especially at the level of the calculation of the limits of this type of function, which proves to be simpler. However, the interpretations of these limits constitute an obstacle for $65 \%$ (79 students), who do not succeed in overcoming this difficulty. In fact, the majority of the students do not assimilate the concepts of asymptotic direction and asymptotic line. This is due, to a great extent, to the didactic transposition of precisely the knowledge to teach to the knowledge taught of these concepts.

\section{Question 2}

This task deals with the treatment of the algebraic register; it is the study of the sign of $f^{(2)}(x)$. The majority of the students $75 \%$ (92 students) do not succeed in interpreting this sign to define the inflection point. This is due to the fact that this concept comes true in two stages, namely the resolution of the equation $f^{(2)}(x)$ $=0$, and the sign of $f^{(2)}(x)$ which changes at points where this second derivative vanishes. We note that the school textbooks are not much interested in the diversification of activities dealing with the concept of the inflection point. This review concerns the didactic transposition of the teaching of the same concept because the school textbooks already constitute an internal transposition of the knowledge to teach, as it is defined by the ministry guidelines, to the knowledge indeed taught in classes (Mr. Artaud (1997)). Our worry as regards the inflection point is focused on the conversion of the sign of the second derivative of the function being discussed in graphic register, then on the treatment within this register especially at the level of the change of concavity of the graphic representation of the studied function. The articulation between the algebraic register which manifests itself by the study of the sign of $f^{(2)}(x)$ and the graphic register conveyed by the study of the concavity of $\left(C_{f}\right)$, poses some problems to $55 \%$ ( 67 students), who have difficulties at the level of this articulation.

\section{Question 3}

We notice that the construction of the graphic representation constitutes a major difficulty to the students of the first year experimental sciences. At the level of the treatment within the graphic register, $60 \%$ (73 students) do not succeed in drawing the tangent (D) in the curve $\left(C_{f}\right)$ in one single point in a more precise way. This difficulty originates in the lack of activities which treat this type of task. In this respect, we notice that the majority of the students cannot draw the tangent $(D)$ so that the point of meeting with $\left(C_{f}\right)$ is reduced to a single point, but we also notice that these students draw almost a segment as being a point of meeting; this is due to the fact that these students do not work with rigor during graphic representation, which makes it necessary to stress the importance of defining a concept during the execution of a task linked to this concept. Certainly, the student is aware that the tangent point it is a point but when drawing it, it is assimilated as a segment which touches the curve in a point. This difficulty is a consequence of the didactic transposition which prevents these students from optimizing this task, since the teaching of the tangent line takes up a marginal part in the school textbooks.

The task linked to the line of graphic representation $\left(C_{f}\right)$ constitutes a true difficulty to which the students are confronted; $80 \%$ of these students do not succeed in overcoming this difficulty owing to didactic transposition. In fact, the teaching of this concept must stress the articulation between both modes of functionalities of graphic representations:

- Ideogrammatic (putting the emphasis on the global aspect of the graphic representations)

- Nomograph (being interested in the local aspect of the graphic representations). 


\section{Second activity:}

\section{Question 1}

The notion of limit really poses cognitive problems according to several researchers such as Mrs $\mathrm{H}$. Elbouazzaoui (1988) and N. Mawfik (2006). In fact, 71,50\% ( 87 students) have difficulties in calculating the limits of the function $\mathrm{g}$ to the right and to the left of 0 . This difficulty is also considered from an epistemological dimension because these students are usually accustomed to treating the limits of functions without refering to those of right or left of a given point. However, $90 \%$ of the students find the limits of $g$ in $+\infty$ and in $-\infty$ easily. Moreover, didactic transposition plays a very important role in the limitation of the obstacles which prevent the students from overcoming these difficulties linked to the notion of the limit.

\section{Question 2}

In this question, with the aid of appropriate activities, we make sure that the student performs her/his tasks in relation with our issue dealing with difficulties hindering the realization of the graphic representation of a function. This question can be tackled following two methods: A minority of the students who treats it by the method of calculating $\lim |x| \rightarrow+\infty f(x)-(x+1)=0$, to maintain that the line of the equation $y=x+1$ is an asymptote of $(\mathrm{Cg})$. On the other hand, the majority of the students follow the classical method which consists of

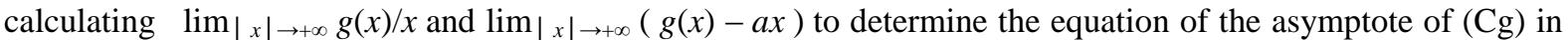
neighborhood of $+\infty$ and of $-\infty$, as we have pointed out before. The majority of these students have difficulties in finding the equation of this line because of the problems related to the notion of the limit itself. This has serious repercussions on the graphic representation. The gradual elaboration of the notion of the limit in the first year, experimental sciences is only based on few examples and all teachers show that the assimilation of this concept remains inaccessible for most the students (Alper and Enver, (2011)). Hence a big question arises about the didactic transposition of the teaching of the notion of the limit of a function.

\section{Question 3}

The articulation between the study of the sign of $g(x)-(x+1)$ which appears as part of the algebraic register and that of the graphic register, which are translated by the position between the graphic representation $\left(C_{g}\right)$ of the function $g$ and the tangent line $(T)$, causes a bigger problem to $68 \%$ (83 students), who do not succeed in accomplishing this task. This is due to the fact that these activities hardly exist in the school textbooks, and even the ministry guidelines do not stress them much.

\section{Question 4}

As we have already pointed out, a good graphic representation follows a strict progression namely the construction of the vertical asymptote of the equation $x=0$ and that of the oblique asymptote of the equation $y=x+1$.

Besides, by getting closer to the tangent $(T)$, we note that the majority of the students $(70 \%)$ draw the curve $\left(C_{g}\right)$ as being a parallel line in $(T)$. This difficulty of both cognitive and epistemological nature comes first from the fact that the student does not assimilate well the notions of asymptote and asymptotic direction, second, this student, being in trouble, is accustomed to drawing curves as being curves of affine functions or linear functions.

\section{Third activity: \\ Question 1}

In this question, the overwhelming majority $(73 \%)$ of the students fail to find the domain of the definition of the function $h$ starting from its graphic representation. This comes from the fact that these students have the habit of finding $D_{h}$ from the algebraic expression of the function $\mathrm{h}$. In this sense, most students tend to proceed the conversion of the graphic register to the algebraic register, by trying to search for the algebraic expression of the function $h$ from $\left(C_{h}\right)$ in order to determine the domain of definition $D_{h}$. On the other hand, we point out that 27 $\%$ of the students find $D_{h}$ successfully, by relying on the treatment within the graphic register.

\section{Question 2}

In this activity, the student does a task of the treatment of the graphic register by examining her/his capacity to deduce and to determine more particular limits from the graphic representation of a function.

We have noticed that $35 \%$ ( 43 students) succeed in seeing that $\lim _{x \rightarrow+\infty} h(x) / x=0$, from the fact that the axis of the abscissa is an asymptotic direction in neighborhood of $+\infty$, as opposed to $65 \%$ of the students who have difficulties in accomplishing this task, some among them write $\lim _{x \rightarrow+\infty} h(x) / x=\frac{1}{2}$; this difficulty is of cognitive nature because these students merge the asymptote of equation $y=\frac{1}{2} x+1$ with the $x$-axis which is an 
asymptotic direction. As regards $\lim _{x \rightarrow-\infty} h(x) / x$, we notice that $60 \%$ ( 73 students) do not answer this question as opposed to $40 \%$ ( 49 students )who give the expected answer, by writing $\lim _{x \rightarrow-\infty} h(\mathrm{x}) / x=\frac{1}{2}$. This is caused by the conversion of the graphic register to the algebraic register, which constitutes an epistemological break, due to the didactic contract, in the sense of G. Brousseau (1988). That is the student is accustomed to representing the function graphically from its algebraic expression, which makes the passage to the reverse operation a new task for the student of the first year Baccalaureate experimental sciences. Besides, this difficulty is reinforced by the didactic transposition of this knowledge in the school textbooks. We find there are several various activities which stress the conversion of the algebraic register to the graphic register; however, there is almost a marginalization of the conversion of the graphic register to the algebraic register. Moreover, the ministry guidelines and curriculum of mathematics in Morocco, or even Baccalaureate exams leave the graphic representation as the last question to be treated in a problem linked to the study of the function.

\subsection{Qualitative analyses of the oral productions of the students}

To supplement our statistical analyses, we asked 24 students about the big difficulties they are confronted to, in order to know if the adopted didactic transposition prevents the solving of different tasks linked to the graphic representation of a function.

As for the pedagogic dimension, we notice that 12 students declare that the cause of these difficulties lie in the manner this concept is dealt with.

Since the curriculum is too much loaded, the teacher does not have enough time to diversify activities linked to the graphic representations of functions, and later, conceptualize different types of registers, by interpreting all expressions, namely $\lim _{|x| \rightarrow+\infty} f(x) / x, \lim _{|x| \rightarrow+\infty} f(x)-(a x+b)$. So, the teacher contents herself/himself with minimizing the quantity and diversity of activities treating these concepts. Besides, the teacher does not have time to link and interpret the results of $\lim _{|x| \rightarrow+\infty} f(x) / x=0, \lim _{|x| \rightarrow+\infty} f(x) / x=+\infty$, $\infty$ and $\lim _{|x| \rightarrow+\infty} f(x)-(a x+b)$ with appropriate graphic representations.

Furthermore, the teacher handles problems or exercises which require a considerable time such as the determination of the domain of the definition, the calculation of the limits of the function, the determination of the derivate function, the drawing of the variations table, the determination of the infinite branches, the inflection point and finally the layout of the graphic representation. To accomplish all this, we need a lot of time. As a result, the teacher contents himself or herself with giving the students 2 or 3 exercises which do not guarantee the assimilation of the treatment of the graphic representation of a function and the good conversion of the algebraic register to the graphic register.

Knowing that the language of teaching mathematics is Arabic, we illustrate the difficulty linked to the pedagogic dimension, by the production of a student (fig.a).

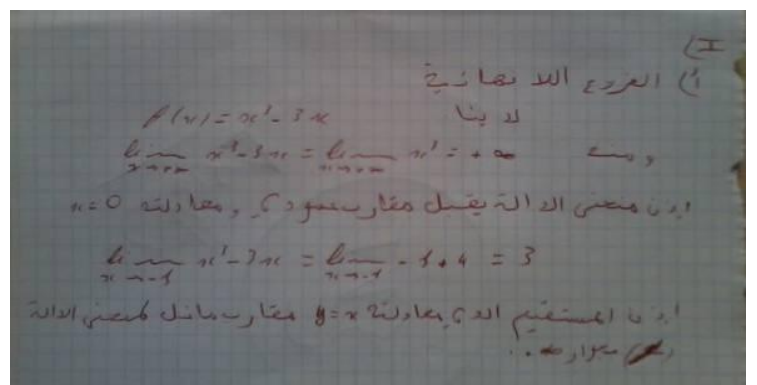

fig. a

We notice that this student does not succeed in interpreting the limit of the function $f$ graphically when $x$ tends towards $+\infty$; she or he deduces from $\lim _{x \rightarrow+\infty} f(x)=+\infty$ that the curve of $\mathrm{f}$ accepts a vertical asymptote of the equation $x=0$. Also, this student concludes from $\lim _{x \rightarrow-1} f(x)=3$ that the line of the equation $y=x$, is an oblique asymptote of the curve of $f$. We can conclude from this that this student is far from being able to assimilate the notion of the graphic representation of a function.

Moreover, 8 students declare that their difficulties are of cognitive nature; in fact, these students have difficulties in the articulation between the limits: $\lim _{|x| \rightarrow+\infty} f(x) / x=0, \lim _{|x| \rightarrow+\infty} f(x) / x=+\infty,-\infty$ and $\lim _{|x| \rightarrow+\infty} f(x)-(a x+b)$ by interpreting them geometrically in a correct way. More than that, these students experience difficulty in drawing the curve by respecting asymptotes or the asymptotic directions to perceive more precisely the concavity of the curve. As a result, these students suggest a method concerning the teaching of the graphic representation of a function in such a way as to give more importance to activities relating to the treatment of the graphic register and the conversion of the algebraic register to the graphic register, and by providing various, well chosen activities. According to this vision, it is necessary for us to call into question the 
curriculum of mathematics notably the teaching of the graphic representation of a function to help the students in trouble with this matter.

As for difficulty of cognitive nature, we introduce the production of two students who are confronted with problems on this matter. The first student does not succeed in accomplishing the conversion of the symbolic register (variations table) towards that of graphic register of the function $g$ (fig.b), whereas the other one does not succeed in deducting the results of limits of the function $\mathrm{h}$ from its graphic representation $\left(C_{h}\right)$, that is to say, he or she has the problem of the conversion of the graphic register towards the algebraic register (fig.c).

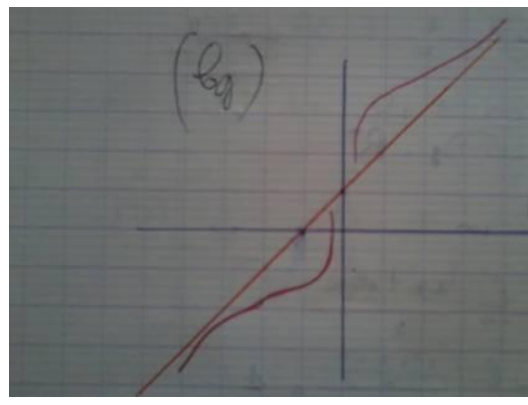

fig. $b$

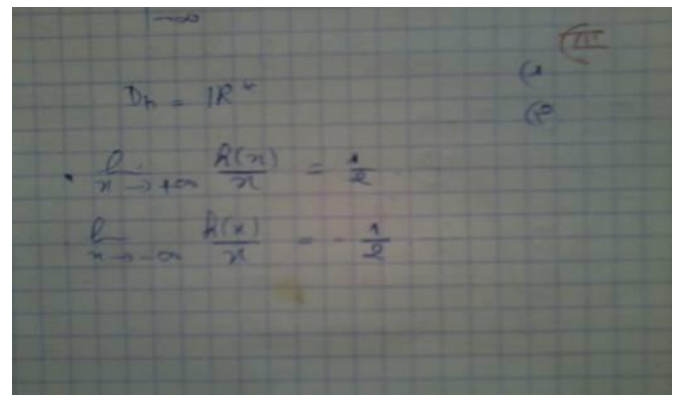

fig. c

However, there are only 4 students who answered the questions easily.

\section{Conclusion}

As a conclusion to this study, we can say that for the students in difficulties with the graphic representation of a function, it would be necessary to follow, in the teaching of this concept, a progression adapted to the students, to offer situations which take into consideration the different registers of representations. Besides, these students are very badly prepared for practicing efficiently the functionalities of graphic representations be them ideogrammatic (those who put the emphasis on the total aspect of the graphic representations) or nomograph (those who put the emphasis on the local aspect of the graphic representations).

Finally, the didactic transposition of the notion of the curve should follow a finer and more strict progression so that the students in trouble can become able to solve different tasks, be it the treatment in the graphic register or the conversion of algebraic register to the graphic register and conversely in relation to the graphic representation of a function.

\section{References}

[1]. Alper, ç. Enver, T (2011). Diagnosing learning difficulties related to the equation and inequality that contain terms with absolute value, International Online Journal of Educational Sciences, 3(2), 461-473.

[2]. Artaud, M. (1997). Introduction à l'approche écologique du didactique. L'écologie des organisations mathématiques et didactique. Actes de la LX ${ }^{0}$ école d'été de didactique des mathématiques, Houlgate, pp . 101-139.

[3]. Artigue, M. (1989). Ingénierie didactique. Recherche en didactique des mathématiques, vol 9, nº 3, $282-307$.

[4]. Badaoui, B., Yadini, H., Zghari, H., \&Bhir, S. (August, 2006) Textbooks of mathematics, first year Baccalaureate, section experimental sciences. Edition of the national education. Italy, Canale Press

[5]. Bloch, I. (2000). L'enseignement de l'analyse à la charnière lycée / université : savoirs, connaissances et conditions relatives à la validation. Thèse de doctorat, Université de Bordeaux 1.

[6]. Bloch, I. (2002). Un milieu graphique pour l'apprentissage de la notion de fonction au lycée. Petit x, nº : 58, 25-46.

[7]. Brousseau, G. (1988). Le contrat didactique : Le milieu. Recherche en didactique des mathématiques, vol 7, $\mathrm{n}^{\circ} 2,309-336$.

[8]. Chauvat, G. (1998-99). Courbes et fonctions au collège. Petit x, n⿳⺈ 51, 23-44, Grenoble.

[9]. Chevallard,Y.(1985). La transposition didactique du savoir savant au savoir enseigné. La pensée sauvage. Grenoble.

[10]. Commission Spéciale Education-Formation: COSEF. (1999). Charte Nationale d'Education et de Formation. Disponible sur : http://www.men.gov.ma/sites/fr/Lists/Pages/charte.aspx (consulté le 15/11/2012)

[11]. David, B. Kostas, N et Laurent, V. (2012). Registre et praxis numérique en fin de première année de primaire. Annales de didactique et de sciences cognitives. Vol 17, 59-86

[12]. Duval, R. (1993) Registres de représentation sémiotique et fonctionnement cognitif de la pensé. Annales de la didactique et de Sciences Cognitives, $n^{\circ}$ 5, 37-65. IREM de Strasbourg.

[13]. Duval, R. (1995). Sémiosis et pensé humaine : Registres sémiotiques et apprentissage intellectuels. Berne : Peter Lang.

[14]. Elbouazzaoui, H.(1988). Conceptions des élèves et des professeurs à propos de la notion de la continuité d'une fonction. Thèse de doctorat. Université Laval. Québec. Canada.

[15]. Guzman-Retamal, I. (1989). Registre mis en jeu par la notion de fonction, Annales de Didactique et de Sciences Cognitives, $\mathrm{n}^{\circ} 2$, 229-259. IREM de Strasbourg.

[16]. Lacasta, E. (1995). Les graphiques cartésiens de fonctions dans l'enseignement secondaire des mathématiques : illusions et contrôle. Thèse de doctorat, Université Bordeaux I.

[17]. Lémonidis, E.C. (1990). Conception, Réalisation et Résultats d'une expérience d'enseignement de l'homothétie, Strasbourg, Thèse de doctorat, Université Louis Pasteur.

[18]. Moreno, J. (2006). Articulation des registres graphiques et symbolique pour l'étude des équations différentielles avec CabriGéomètre. Analyse des difficultés des étudiants et du rôle du logiciel. Thèse de doctorat, Université Joseph Fourier-Grenoble 1.

[19]. Maschietto, M . (2001).Fonctionnalités des représentations graphiques dans la résolution de problèmes d'analyse à l'Université. Recherches en Didactique des Mathématiques, vol 21, $\mathrm{n}^{0} 1.2, \mathrm{pp} ; 123-156$. 
[20]. Mawfik, N.(2006). Compréhension de la notion de continuité d'une fonction numérique à variable réelle chez les élèves du secondaire marocain. RADISMA numéro 1.

[21]. Montaj, A., Khayli, S., Hilmi M., Blkhayat, M., Borhim, M., Brwa, H. \& Jamal, A. (July ,2006). Textbooks of mathematics, first year Baccalaureate, section experimental sciences. Edition of the national education. Madrid, Spain : Printex Press.

[22]. Padilla Sanchez, V. (1992). L'influence d'une acquisition de traitements purement figuraux pour l'apprentissage des mathématiques, Strasbourg, Thèse de doctorat, Université Louis Pasteur.

[23]. Ravel, L. (2003). Des programmes à la classe : étude de la transposition didactique interne. Exemple de l'arithmétique en Terminale $\mathrm{S}$ spécialité mathématique. Thèse de doctorat, Université Joseph Fourier, Grenoble I.

[24]. Sarrasy, B. (1995). Le contrat didactique. Revue Française de Pédagogie, $\mathrm{n}^{\circ}$ 112, 85-118

[25]. Tavignot, P. (1995). à propos de la transposition didactique en didactique des Mathématiques. SPIRALE-Revue de Recherche en éducation, $\mathrm{n}^{0} 15,31-60$.

[26]. The kingdom of Morocco, Ministry of national education, higher education and vocational education.(2007) Maths guidelines for secondary schools. Rabat, Morocco: Nadia Publishing Company.

[27]. Tall, D. O. \& Razali, M. R. (1993). Diagnosing students' difficulties in learning mathematics. International Journal of Mathematical Education in Science and Technology, 24(2), 209-222.

[28]. Vandebrouck, F. (2011). Perspective et domaines de travail pour l'étude des fonctions. Annales de didactique et de Sciences Cognitives, $n^{\circ} 16,149-185$ 